University of Nebraska - Lincoln

DigitalCommons@University of Nebraska - Lincoln

Faculty Publications - Department of

Philosophy

Philosophy, Department of

1997

\title{
Pragmatism, Internalism, and the Authority of Claims
}

Dan D. Crawford

University of Nebraska - Lincoln, dcrawford1@unl.edu

Follow this and additional works at: https://digitalcommons.unl.edu/philosfacpub

Part of the Philosophy Commons

Crawford, Dan D., "Pragmatism, Internalism, and the Authority of Claims" (1997). Faculty Publications Department of Philosophy. 4.

https://digitalcommons.unl.edu/philosfacpub/4

This Article is brought to you for free and open access by the Philosophy, Department of at DigitalCommons@University of Nebraska - Lincoln. It has been accepted for inclusion in Faculty Publications Department of Philosophy by an authorized administrator of DigitalCommons@University of Nebraska - Lincoln. 
Published in Pacific Philosophical Quarterly 78 (1997), pp. 63-77.

Copyright (C) 1997 University of Southern California. Published by

Blackwell Publishers. Used by permission.

\title{
Pragmatism, Internalism, and the Authority of Claims
}

\author{
Dan D. Crawford
}

\begin{abstract}
This paper develops and defends an internalist account of having authority for one's claim. It begins with Robert Brandom's pragmatist account of thinking which locates the root notion of reasoning in a primitive language game of asking for and giving reasons. The idea is that the authority of a claim can be spelled out pragmatically in terms of the social practice of undertaking commitments and attributing entitlements. It is argued that this account fails to acknowledge the role of the subject's grasp of the higher-order concept of the evidence on which I base my claim.
\end{abstract}

Some claims that a person makes have authority for the one who

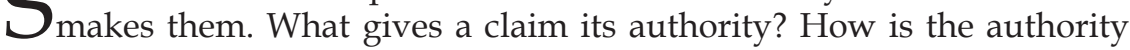
of a claim tied to the internal states of the one who makes it? How much does a person have to know about the authority of his or her claim in order to be fully justified in making that claim?

This is the constellation of questions I will be considering in this paper. They are all epistemological questions centering mainly on the requirements for a claim's having authority. My discussion of them will be couched within the current internalism/externalism debate that has been prominent in epistemology for the last decade. However, I want to approach these questions by a somewhat indirect path, by looking at a theory of cognition that was developed by Robert Brandom in a series of papers, and fully synthesized in the recent book, Making It Explicit. ${ }^{1}$ One of Brandom's central concerns is: what is it to be in a cognitive state? Or, since his approach is avowedly "pragmatist", the question should be put 
in terms of an external performance: what is it to make a cognitive claim? Brandom's answer to this question, in a nutshell, and put in a way that stands in need of pragmatic elucidation, is that a person makes a cognitive claim only if she understands the significance of her claim.

When the issue is put this way, it seems to fall squarely within the domain of the philosophy of mind and cognitive science. And indeed, much of Brandom's discussion has to do with elucidating the character of significant thought, of laying bare the necessary components of making a cognitive claim. But there is a further dimension of this account that chimes with the concerns of cognitivists, and that is the attempt to construct a model of the development of thought, to trace the way in which humans have passed from primitive forms of thinking and reasoning to fully-fledged thinking and reasoning. In fact, Brandom combines these two projects - the analytical and historical - into one: we can discern the essential elements of our higher cognitive activities in the humbler conducts and engagements of our remote cognitive ancestors.

Brandom's proposed pragmatic account of what is involved when a subject grasps the significance of her claim is fraught with meaning for the sorts of questions about the authority of claims that we raised at the outset. For as we shall see, the pragmatic view ties the notion of making a claim and grasping its significance to the social practice of asking for and giving reasons for one's claim. Thus the concept of cognitivity that is articulated in this account is linked with the concept of justification by means of the explicative idea of having and giving reasons. I wish to explore this idea that we should understand the authority of a claim (for a subject) in terms of the subject's ability to play the "game" of asking for and giving reasons. And I will further consider how far this account of authority can accommodate an internalist theory of justification.

1.

Before turning to these questions, we need to have a working definition of internalism and a general concept of justification. The concept of justification that I will adopt is that it consists in having (adequate) evidence for one's claim, and basing one's claim on that evidence. ${ }^{2}$ Within this framework we can define four internalist requirements for justification which determine four increasingly strong internalist positions.

(1) The first requirement is the broad one that a claim can only be justified for a subject by something that lies within her perspective, that is, by some other claim the subject makes (or perhaps by the content of such a claim). Or, (to put the point in the first person), whatever makes a claim justified for me must be my evidence; I must be in possession of 
it, have it. It must be either one of my internal states or a constituent of one of my internal states.

(2) The second requirement is that whenever a subject is justified on the basis of some evidence that she possesses, then she is aware of, or has access to, the evidence on which she bases her claim. ${ }^{3}$

(3) A third position adds the further requirement that the subject who is justified not only grasps her evidence, but recognizes (or can come to recognize) that she has adequate evidence for her claim.

(4) Whereas requirements (2) and (3) allow for weaker internalist views that make the subject's grasp of her evidence a wholly dispositional matter, the fourth position eliminates that option and requires that the subject has evidence for her claim in the strong sense that she is actively thinking of the evidence on which her claim is based, and actively recognizes that her claim is justified by that evidence. The intuition here is that a claim can only be justified for a subject by the evidence she has for it (and based on that evidence) if she is utilizing that evidence and relying upon it at the time the claim is made.

I will define the opposing externalist view in contrast to the first two requirements pertaining to what can justify a claim: on this view a claim is justified by factors or processes that lie outside the subject's perspective, that is, factors that are not any of the subject's beliefs or claims and that may fall completely outside the subject's awareness.

\section{2.}

We can begin to get at Brandom's position on these various interconnected topics by looking at his discussion of what distinguishes human (cognitive) performances from non-human responses which reliably discriminate objects in their environment. Take for example the observation report "It's getting warmer". What is the difference between "a parrot trained to utter 'It's getting warmer' when exposed to suitable changes of temperature and the human observer who reports the same condition"? (VU, 32) Brandom points out that: "Any physical object classifies its environment, or more strictly the stimuli impinging on it, insofar as it responds differentially to those stimuli ... In an oxygenated environment, a chunk of iron rusts in the presence of water, and not in the presence of oil. By responding either way, the iron classifies its environment" (VU, 32). But the difference does not lie here: both parrot and human responses may differentiate the same, or nearly the same, class of environmental objects. "[The difference] lies rather in the understanding of the classificatory significance attributed to those responses which is exhibited by the one whose responses they are" (VU, 32). 
How then does the pragmatist understand this understanding of the significance of a response by the one whose response it is? Brandom explains his own pragmatist approach by contrasting it with what he calls the "platonist" approach to human understanding which sees it as "an essentially principled affair." "Behind every practical human capacity which exhibits understanding is to be found a principle governing that practice. Understanding is a matter of grasping such principles, and subsequently of applying or following them" (VU, 27). By contrast, "the pragmatist strategy is to try to explain understanding that something is the case in terms of understanding how to do something, and further to understand understanding how in the first instance simply as being able to do something, to perform appropriately according to some practice" (VU, 28). For the pragmatist, practice is prior to principle, and understanding is viewed as mastery of the appropriate conducts of a social practice.

To return to our human observer who utters "it's getting warmer," his understanding of the significance of his report is explicable in terms of "further practical dispositions of the performer" (VU, 33). To a first approximation, it consists in a "practical mastery of the inferential role of the response," the ability to "[distinguish] between what follows from that content and what does not, and between what it follows from and what not" (VU, 33). Brandom, then, uses an inferential model to explain both how a performance acquires content or significance - by virtue of being caught up in a verbal practice, and how subjects grasp this content - by being able to make correct inferences and distinguish them from incorrect ones. Although examples are not plentiful in these essays, the most frequently used illustration of an inferential role is the family of color predicates: when the parrot utters "this is red", it does not go on to infer "this is not green" or "this is not a prime number". That is, it does not exhibit a grasp of the inferential and incompatibility relations between color claims.

But humans do. And the pragmatist's claim is that when an observer moves from "this is red" to "this is not green", this is not a "principled affair", at least not "in the first instance". It is not to be explained in terms of the subject's bringing his performance under some explicitly formulated rule or principle (such as that an object can only have one color at one time and in the same respect). The pragmatist understands understanding in terms of an ability to make the correct inferential moves. And this implies that humans can make inferences without having to grasp any general principles. Now if all this means is that in ordinary contexts, humans can make inferences without bringing to mind or entertaining the general principles that warrant them, then the claim is mildly unexciting, although certainly arguable. But in fact, a much stronger claim is implicit in these remarks, for Brandom is introducing a level of inference 
that can be wholly explained in terms of (correct) moves from premise to conclusion, and without the mediation of any generalization. The idea originates in Sellars who called these moves "material inferences". Material inferences occur at a level that does not presuppose that the inferrer has explicitly mastered the logical expressions "all", "some", "if-then", "not." To illustrate, let us use Sellars' classic, indeed paradigmatic, example of a material inference

Smoke is present, so fire is nearby.

One who makes this inference does not (necessarily) formulate or utilize, either consciously or unconsciously, the generalization that whenever there is smoke there is fire. The inference is non-enthymematic, moving directly from the particular premise to the particular conclusion. Subjects correctly move from the premise "smoke is present" to the conclusion "fire is nearby", and also make additional moves from the latter as premise, e.g., to the conclusion that going over there is going to fire. But since material inferential activity may occur even if the inferrer lacks the ability to wield formal logical expressions, we will call inference at this level proto-logical. ${ }^{4}$

We may well ask at this juncture what makes the performances of these subjects who have begun to master an inferential role genuine inferences, that is, instances of reasoning, and not just somewhat more complex discriminative responses? What permits us to say that the human subject understands his conclusion ("so fire nearby") as the conclusion of an inference? Brandom's answer, as I interpret him, is that the human's inferences are bound up with the social practice or game of asking for and giving reasons.

How is the game of giving reasons played? First, Brandom follows Sellars in emphasizing its distinctively normative character. It is a discursive practice that "essentially includes assessments of moves as correct or incorrect, appropriate or inappropriate" (MIE, 159). These assessments in turn involve the attribution (to players) of the "deontic statuses" of commitment and entitlement. With regard to commitment, the one to whom a claim-commitment is attributed is committed, first, to a course of inferential conduct and to making his responses conform to a set of appropriatenesses. Further, a claim-commitment involves the endorsement (by the subject) of further claims, namely those that follow from it as conclusions. But more is involved, for "one not only authorizes further assertions, but commits oneself to vindicate the original claim, showing that one is entitled to make it" (ASS, 641). Specifically, one undertakes the "task-responsibility" to justify the claim if challenged, by giving a reason for the claim that responds to the challenge. This commitment to defend one's claim allows one to authorize others "to re-assert the content 
of one's claim, and hence to employ it as a premise in their own deliberations and justifications" (VU, 35).

A central theme in this account is what I would call the primacy of inference. Brandom clearly thinks that inferring is the primary activity of cognitive beings and seeks to explain justificatory contexts in terms of inferential ones. The activity of giving reasons is for him simply a special use or application of one's mastery of an inferential role in the special context of challenging and defending claims. Thus, he avers that the way one defends a claim against a challenge is by "producing further assertions whose contents are appropriately inferentially related to the original one" (ASS, 642). His idea is that the reasons we have and give for claims are just the premises of our (correct) material inferences. Thus giving a reason for a claim is, in the first instance, nothing more nor less than saying what that claim follows from. And further, any claim can become a reason for some other claim that follows from it as conclusion. He concludes that "[i]nference is thus the root notion from which are elaborated both the justificatory responsibility one commits oneself to in asserting, and the assertion license issued thereby" (ASS, 642).

A second theme is that the inferential activities that fall under this basic notion of inference take place at a level that does not presuppose formal-logical vocabulary and competencies. Specifically, it is the notion of protological, material inferential reasoning, with its coordinate practice of challenging and defending claims, that serves as the basis for the concept of justification that we have just described. Thus, along with proto-logical inferring, Brandom has delineated a level of proto-justificatory activity (defending claims) that does not presuppose a mastery of formal-logical or epistemic vocabulary. But we may wonder, at this point, why Brandom goes to all the trouble to explicate inference and justification in terms of primitive logical abilities rather than fully developed, formal ones? What is gained by sketching this intermediate logical position on the road to fully-fledged rationality?

We can find a partial answer to this question by reconsidering the pragmatist's strategy. As we have seen, Brandom is attempting to find the "root notion" from which our full-blown concept is derived. And his pragmatist commitment is to the idea that this root notion can be spelled out entirely in terms of the (outward) conducts of attributing (and acknowledging) commitments and entitlements, and that a robust sense of these deontic activities can be given using only proto-logical resources. So the more problematic is being explicated in terms of the less problematic. A second motive is that he wishes to avoid accounts of justification that are "principled affairs". At some level, the subject's claims must have authority even though the subject does not explicitly grasp the (epistemic) principle involved.

In the remainder of this paper, we will ask whether Brandom has elicited the central meaning of a claim's having authority for the one who 
makes it, and whether he has succeeded in grounding this account in protological reasoning. I will argue that Brandom has successfully isolated what I will call a manifest root-component of our concept of justification, which however needs to be extended and enriched in order to explain adequately our common sense of being justified and of having authority for our claims. To achieve this, I will attempt to construct an illustrative example that concretizes all of the general points we have been discussing - an example of a justificatory context that illustrates how the game of asking for and giving reasons is played at the proto-logical level, and how it builds upon material inferential skills. ${ }^{5}$

We will imagine a primitive cognitive community whose members are good at making material inferences and correcting each other when they mis-infer, and we will envision circumstances in which one of them might be called upon to express a reason for one of his claims. And we will continue to acknowledge Brandom's provocative idea that these beings might engage in the practice of having and giving reasons - one that exhibits a robust sense of the authority of their claims, while lacking a formal-logical vocabulary. ${ }^{6}$

It will facilitate our task if we can assume that our proto-reasoners have some grasp of the concept of negation. As material inferrers they have already mastered the proto-logical expression "so". We will now equip them with a primitive idea of negation that has the force of "no such-and-such there", that is, the absence of something, there isn't a thing there where one expects it to be, it isn't around, it's gone. To distinguish this primitive idea of negation from its sophisticated logical counterpart, let us introduce the expression "nok" into our proto-reasoners' vocabulary. If one of them opens the drawer where he keeps his socks and finds that the socks are gone, his perceptual report in that situation is "nok socks". Or if one expects to find fire somewhere, but does not find it, she utters "nok fire here". The claim "nok fire" could follow from other premises, e.g. "the oven feels cold," or it could be a perceptual claim (a response to one's looking into a cold, dark oven). What might follow from it is: "We eat cold spaghetti tonight," or "Let's go gather some sticks to build a fire."

It should be noted that we might also seek a basis for negation in the non-verbal conduct of the subject, viz., in the act of rejecting a claim. After failing to find socks in the drawer, the subject rejects "Socks are there in the drawer," with suitable rejecting bodily behavior (involving hands or head?). ${ }^{7}$ In fact, the expression "nok fire" as I defined it is functionally equivalent to such rejecting behavior. I will assume that our proto-reasoners have a practice of rejecting a claim and the use of "nok".

George and Louise are looking for fire. Their spoken thoughts might be expressed in the following dialogue (with appropriate commentary added): 
Both express the object of their search by wondering where fire is and expressing their intention to find it: Fire is present, where? I will go to fire. ${ }^{8}$

Both see smoke in the distance, and materially infer (jubilantly): Smoke is present, so fire is nearby.

Another inference: Fire nearby, so going over there is going to fire. So I will go over there.

As they head toward the place where they expect to find fire, they express their expectation by uttering: Fire is in this nearby place.

But when they do not find fire in that place, they utter: Nok fire in this place.

After a lengthy but futile search in several likely places, George announces: Nok fire here.

Louise continues to assert: Fire is nearby, and is baffled by George's claim "Nok fire here." She recalls the smoke they saw and the inference they both made ("Smoke is present, so fire is nearby.") She not only rejects George's claim "Nok fire here", but queries it in a way that expresses her intention that George give an accounting for his claim (perhaps with a querying cum rejecting tone): You just uttered 'nok fire here' when smoke is (was) clearly present?

George responds: We have looked for fire in these likely places with the outcome of nok fire in these places, so nok fire here. George's inference presupposes that he has some awareness of what he is doing with Louise and of the outcome (or expected outcome) of their activity. When he sees that this expected outcome has not materialized, he finally rejects it. ${ }^{9}$ And the crucial point is that he rejects it because (for the reason that) they have made a futile search. What makes this fact his reason and not merely a causal antecedent of his claim is that it is (or later becomes) the premise of a material inference which he gives in defense of his claim. ${ }^{10}$

George has responded to Louise by producing a correct pattern of inferential reasoning, that is, by linking his conclusion-claim to the premise-claim of such a pattern. He vindicates his claim by putting it into such a pattern of acceptable inference. The story has a happy ending. Louise recognizes that George has produced a good inference and that his puzzling claim does after all follow after a premise that she accepts, and so she is now inclined to accept George's claim (and withdraw her own). After a good deal of head-scratching, and reasserting of her own incompatible material inference, Louise finally yields. 
Having seen how proto-reasoners might play the game of giving and asking for reasons at the level of material inference, we are in a position to understand Brandom's claim that at this level, "[c]ommitments to material contents could be discussed, challenged, redeemed, withdrawn" (VU, 38). Challenging a claim would involve putting a claim into question, querying it in a context in which it conflicted with another claim that was secured by some common knowledge or some readily available premisefact. Defending a claim would be putting forward a candidate premise from which the original claim followed. Discussion would center on this premise and whether it was strong enough to force the acceptance of its conclusion. Redeeming a claim would be offering an acceptable premise, viz., one that met the challenge. And withdrawing a claim would be ceasing to make the claim (or rejecting it) if one could not defend it. ${ }^{11}$

How then does the pragmatist view of justification stand with respect to internalism? We can now see that Brandom is (just about) in agreement with the first three internalist positions outlined above. First, he seems to accept the internalist's general conception of justification as having evidence or grounds for one's belief or claim, insofar as entitlement is linked to being in the "logical space" of asking for and giving reasons. A subject whose claim is justified has a reason for it and bases her claim on that reason, in the sense that she can vindicate that claim (in response to a challenge). Moreover, what justifies a claim is another claim, viz., the premise-claim of an inference. And further, one who makes a claim has access to the evidence on which her claim is based, because in the standard case she can give her reason. ${ }^{12}$

But the situation is not so clear with regard to the third internalist requirement - that the subject must (be able to) recognize that her claim is justified by the evidence she has. I think that Brandom does want to say that a proto-reasoner recognizes the authority of her claim, but as before, this awareness must be understood in terms of what the subject can do. We can get at this point by considering, first, whether protoreasoners have a concept of having a reason and of giving a reason for a claim. Of course they do, insofar as they understand the practice of challenging a claim, that is, the circumstances in which a claim is appropriately challenged, and how to respond to such a challenge. In the specific case, George recognizes that his claim is incompatible with Louise's claim, and that his commitment to his own conclusion carries with it a rejection of Louise's. Moreover he realizes that Louise's claim is a rival claim that challenges his own and that his entitlement can only be maintained by giving a good reason. Secondly, George has the idea of having authority for his claim insofar as he recognizes that he has a reason for it and is basing his claim on that reason, where this recognition is understood in terms of his readiness to give this reason if called upon to do so. Brandom has 
enabled us to see how one's ability to play the game of recognizing challenges and responding to them exhibits pragmatically his understanding of the concepts of having a reason for a claim and of having authority, even if the subject does not have the expressions "my reason is such-andsuch" or "I am authoritative about such-and-such" in his vocabulary. ${ }^{13}$ Thus Brandom has succeeded in explicating a clear sense of recognizing one's authority, but it is one that does not involve any higher-order thinking about the activity of giving reasons, and so does not require the meta-vocabulary that would be necessary to talk about it. ${ }^{14}$ I will return in a moment to the question of whether this account does fully explicate our concept of having authority.

Brandom of course does not accept the strongest version of internalism, viz., the requirement that a subject is actively thinking about her evidence for a claim whenever the claim has authority for her. His view of having evidence is thoroughly dispositional: a subject's authority is explained in terms of her being able to give a reason for a claim - a reason that will become actual only if the subject is faced with an appropriate challenge. However it seems that such a thoroughgoing dispositionalism must be weakened in one respect: one who has a reason for a claim must at least be aware of the kind of reason she would give if challenged, even if she had not thought of the specific reason she might give. Would it make any sense to say that someone's claim was based on a reason if she had no idea what that reason was until she had occasion to think about it? Of course this awareness of the kind of reason she would give can, in turn, be spelled out dispositionally, but the subject must have done some active thinking at some point about the kind of reason she can appeal to in situations of that kind. ${ }^{15}$

What is the source of a claim's authority on this view? What is it that confers authority on a claim? Does the authority arise from the subject's own awareness of her epistemic condition, viz., her being in the "logical space" of reasons and recognizing that she has a reason for her claim that can meet a potential challenge? This would seem to be what the internalist insists upon, but if it is, it is not Brandom's brand of internalism. For there is a more fundamental source of authority on his view coming from outside the subject and originating in the attitudes and conducts of the subject's linguistic peers. Specifically, a subject's claim has authority (for her) only because others have treated claims of that sort as appropriate conclusions from other claims, and as appropriate premises for other claims, in the game of asking for and giving reasons. Having endorsed these inferential moves, they take a player's claim to be a manifestation of a commitment to the correct inferences, and attribute entitlement on that basis. Or in case the subject manifests an incorrect inference, they withhold entitlement and impose the necessary sanctions. Thus when an individual recognizes her own authority, she is acknowledging an authority 
that already exists and that has its origin in the takings and treatings of others. The subject's self-attribution of authority presupposes and is built on the attributions of others.

But, we may ask, should the locus of authority be on the side of the subject who undertakes a claim-commitment and assumes a task responsibility to vindicate the claim if challenged, or on the side of the social practitioners who confer entitlement? By locating the primary source of authority in the social practice, Brandom compromises the internalist position, so that the requirement that the subject herself must grasp her evidence is neither basic nor essential. It is not basic because it is built on the prior conducts of others who have already authorized the inference. And it is not essential because it is possible for a subject's claim to have full authority even if the subject herself does not acknowledge that authority (as Brandom thinks sometimes happens with observational reports (see Note 12)).

The opposing internalist view that I adopt holds that the authority of a claim derives fundamentally from the subject's own attitudes and awarenesses toward that claim, and consequently that third-person attributions of authority are on a par with self-attributions of authority. By this I mean, first, and uncontroversially, that if one can attribute authority to another, then one can also attribute authority to oneself. As a player in the game of giving reasons, I can recognize that you have a reason that can ward off an objection, and thereby grant you entitlement; but equally I can recognize that I have a reason that can ward off an objection, and so claim entitlement for my claim. Secondly, I am making the substantial claim that first-person attributions of authority are fundamental in the sense that we (knowers) can only attribute entitlement to another if the other attributes it to herself. The subject herself must have the same (dispositional) attitudes toward her evidence that others have toward it, if her claim has authority for her. There is, however, this asymmetry in the two positions: she can be justified if we fail to grasp her evidence (in the particular case), but not if she fails to grasp it. ${ }^{16}$ Of course, my subjectcentered internalism presupposes that the subject is a player in a social game of asking for and giving reasons, and this in turn presupposes that the subject's inferences conform to the proprieties of inference that have already been established by the community of speakers. But it is possible to admit this without at the same time according a more fundamental importance to the takings and treatings of others (towards me), as against the takings and treatings of others towards themselves (or of me towards myself). And so it still can be maintained that a subject's claim can only have authority if she has a grasp of her evidence at least to the same extent that anyone else does.

Let us return finally to the difficult question we raised earlier: has Brandom elucidated the fundamental meaning of our common concept 
of being justified and of having authority for a claim? And has he successfully located the root of our concept in practices occurring at the level of proto-logical reasoning? My answer to both questions is a qualified "yes", so all that remains for me to do is spell out Brandom's achievement, and indicate my qualms.

First, then, Brandom has successfully isolated a component of our concept of having authority that is sufficiently rich to be the model upon which our full-blown conception is built. The sense of being justified that he defines in terms of the undertaking of commitments, the attribution of entitlements, and the challenging and redeeming of claims is a very rich concept indeed, and yet there is a sense in which it is still far removed from our ordinary conception. It may be useful to indicate what, in my view, still separates these two conceptions of having authority.

First, Brandom's view of having authority is minimalist in the sense that its normative content is structured entirely on behavioral-observable concepts that are defined in terms of publicly observable (mostly verbal) conducts. The account does not presuppose that subjects who attribute justification are even aware of internal mental states as such. This, by itself, is not an objection, because it is part and parcel of Brandom's pragmatist strategy to give an account of internal cognitive states in terms of outward conducts and social practices. However it is worth pointing out that as soon as internal mental states (good old-fashioned thoughts) are brought into the picture, one's recognition of one's own authority would be radically altered: for one would then grasp one's reason as an internal thought. So we must imagine that at some point in the development of mind, once the linguistic-behavioral role has been conceived as the model for internal thoughts, ${ }^{17}$ the pragmatic-behavioral proto-justificatory role on which our full-blown concept of justification is based is similarly internalized, and the pragmatic notion of (my) commitments and entitlements is thereby extended and greatly enriched. However, while the locus of the reasons one has would shift, their fundamental significance would not be altered.

Secondly, Brandom's view of having authority and of rationality is minimalist in that it is essentially defined in terms of first order responses, while neglecting higher order thinking. Subjects who have authority can cite reasons (if challenged), but they lack higher order concepts that refer to those reasons and that are necessary in order to make claims about them. In particular, as we have seen, proto-reasoners do not need to have an explicit grasp of the higher order concept of the evidence on which I base my claim in order to recognize the authority of their claims. But clearly there is a deeper sense of grasping one's authority which does involve the explicit grasp of this concept. And in order to have this grasp, one would have to be capable of saying things about one's evidence as such, which entails more than simply exhibiting one's evidence (by giv- 
ing a reason). Without such a higher order concept, it is not clear that we can give an adequate account of the practice of discussing and assessing evidence. In our illustrative example, it was the activity of discussing reasons (premise-claims) and their strength that was the most difficult to reconstruct. In fact, there was no discussion: George had nothing to say by way of backing up his belief that his premise-claim was a better indicator of the presence of fire than Louise's. His problem was that he lacked the necessary logical and epistemological concepts to formulate such a belief. And the general problem is that in order to get one's evidence out on the table and discuss it, one needs to have an explicit command of the concept of my evidence for claiming such-and-such. George cannot get very far in discussing his evidence unless he grasps the fact that he has given evidence, and can say things like: "my claim (that) so-and-so supported my claim (that) such-and-such" and from here it is a short step to "I defended my claim (that) such-and-such and defeated Louise's claim (that) such-and-so." Without these enriched concepts, George's recognition of his own authority would consist simply in his ability to meet a challenge by finding another premise-claim from which his initial claim follows. But since his challenger (Louise) will continue to feel the force of her own material inference, then all George can do (short of coercion) is hope that Louise comes to think that his inferential pattern is stronger than hers, and so yields to it. On the minimalist account, the game of asking for and giving reasons doesn't extend any further than this, and neither does George's grasp of the authority of his claim.

Brandom, of course, emphasizes the importance of mastering logical expressions in order to make explicit the full significance of one's material inferential reasoning. I, on the other hand, am pointing to the need to have a mastery of the appropriate epistemic expressions in addition to logical expressions in order to be able to discuss one's evidence, and compare it with the evidence for a counter-claim. Once George is equipped with both the logical 'if-then' and a concept of his own evidence, he is in a position to say things like: "whenever we do a careful search that leads to nok fire, then nok fire," and to move toward seeing that there can be exceptions to rules like this ("... unless someone has recently put out the fire").

Brandom has certainly specified one clear (internalist) sense of a subject's having authority for a claim, namely, that the subject has a good reason for it and can give it in the appropriate context. Moreover, in the normal case, the subject's claim only has authority if she grasps that she can do this. The strength of this analysis is that it locates the pragmatic origins of our ordinary concept of authority. But while it is rich enough to serve as the basis of our common conception, it falls short of explicating that idea. I have argued for a stronger form of internalism which holds that a claim only has authority for a subject in a sense that involves 
her recognition that she can give a reason for it, and can defend it against opposing reasons. To do this, she needs to have a richer vocabulary that includes an explicit grasp of the concept of the evidence on which I base my claim. It is our readiness to defend our claims by means of these sorts of reflective, higher-order claims that accounts for our ordinary sense that we have authority, that we are entitled to those claims. ${ }^{18}$

\section{Notes}

1 Making it Explicit: Reasoning, Representing, and Discursive Commitment (Harvard University Press, 1994) (abbreviated in text as MIE); “Asserting," Nous 17, 1983, pp. 637-50 (abbreviated in text as ASS); "Varieties of Understanding," in Reason and Rationality in Natural Science: A Group of Essays, ed. N. Rescher (University Press of America, 1985), pp. 27-51, (abbreviated in text as VU); “Inference, Expression, and Induction," Philosophical Studies 54, 1988, pp. 257-85.

2 I am drawing on William Alston's defense of this concept of justification as basic in "Concepts of Epistemic Justification," The Monist, 1985.

3 This requirement also partially explicates the intuition that what justifies me must be my evidence.

4 The use of "so" in the inference-prototype ("Smoke is present, so fire is nearby") indicates only that the subject has correctly inferred the conclusion from the premise-claim. But while "so" thus marks a conclusion, it is not a fully logical expression in that it does not license other formal inferences; subjects cannot move from a correct material inference to the corresponding (true) conditional.

5 It is worth noting that I have found very few clear examples of how proto-logical reasoning goes, and none of proto-justificatory contexts, in Brandom's discussion.

6 Brandom clearly intends this when he states that "at the level of material inference and explicitation responsive performances were given explicit contents as claims by being brought within the game of giving and asking for reasons as premises and conclusions. Commitments to material contents could be discussed, challenged, redeemed, withdrawn. At the level of formal inference and explicitation the arguments or inferences connecting and articulating those premises and conclusions become formulable as explicit claim contents which can themselves be discussed, challenged, redeemed, withdrawn" (VU, 38).

7 Sellars adopts this strategy in "Mental Events," Philosophical Studies 39, 1981, p. 342.

8 I assume that George and Louise have a vocabulary with which to express their own actions and hence their own intentional states (I will do such-and-such), while leaving it open whether they also have a meta-vocabulary for describing their intentional states (I intend that such-and-such).

9 We can see here an obvious candidate for proto- modus tollens reasoning.

10 Whether we view these awarenesses as actual graspings or as merely dispositional depends on whether we accept the strongest (fourth) form of internalism; that is, it depends on whether we view George's initial claim "nok fire here" as the conclusion of an inference from the premise "we have looked around for fire with the outcome of nok fire." Although the story can go either way, it would seem that George's giving of a reason in the first instance would be a case of reiterating the premise of an inference he had already asserted. 
11 We could of course enlarge our description of these activities in terms of the undertaking of the relevant claim-commitments and the attribution of entitlements.

12 These points of agreement have to be qualified in light of Brandom's account of the authority of observational reports. In a telling example, he argues that an assessor of some observer's observational report may attribute authority to that observer even though the observer herself does not think that she is reliable. If the report exhibits a reliable differential dispositional response, that is, if it is made in circumstances which the attributor recognizes as being among those in which the reporter is reliable concerning the sort of matters reported, then the subject may be granted entitlement. However, even if the subject herself may fail to appreciate her own reliability, the attributor at least must grasp her situation and be able to vindicate the original report if it is challenged. Thus while the internalist insight is compromised in this account in that the subject herself does not need to 'possess' the evidence that warrants her claim, it is preserved in that some subject must possess it (MIE, pp. 217-21).

13 Can we go even further? Does George grasp the general principle of his inference that whenever one looks in several places for fire with the result of nok fire, then (probably) nok fire is there, because he has a propensity to make material inferences in accord with this principle? And further, does he grasp the relevant evidential principle that a careful search is a better indicator of the presence of fire than seeing smoke from a distance inasmuch as he opts for one of these conclusions and rejects the other in circumstances in which these inferential patterns conflict, and is prepared to back up his conclusion against its counterclaim? In both cases we seem to be putting more weight on the pragmatic analysis than it can bear.

14 Note that insofar as having the concepts of having a reason for a claim and having authority for a claim boil down to the same abilities, they are, pragmatically speaking, the same concept.

15 In our example, George appeals to the fact that he and Louise had looked in several likely places with a negative outcome. In order to be able to produce this reason, he must, at some time, have thought about that type of evidence: he knows how to sum up similar past experiences-cum-outcomes, and he already knows - pragmatically - what sorts of factors are relevant to meet challenges in the particular circumstances he is in, viz., looking around in likely places.

16 Brandom of course holds the reverse of this, maintaining that her claim may have authority even if she fails to grasp her evidence (see Note 12).

17 I am referring to Sellars' famous myth of Jones, who postulates inner episodes of thought on the model of overt sayings in "Empiricism and the Philosophy of Mind," Science, Perception and Reality, Routledge \& Kegan Paul, 1963, p. 183ff.

18 I would like to thank Jay Rosenberg, William Lycan, Mark Lance, Danielle Macbeth, and William Throop for their helpful comments on this paper. 